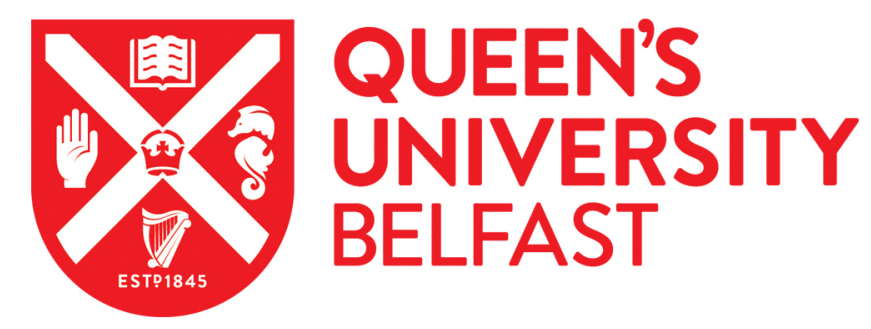

\title{
Enhancing the Activity and Tuning the Mechanism of Formic acid Oxidation at Tetrahexahedral Pt Nanocrystals by Au Decoration
}

Liu, H. X., Tian, N., Brandon, M., Pei, J., Huangfu, Z-C., Zhan, C., Zhou, Z. Y., Hardacre, C., Lin, W., \& Sun, S. G. (2012). Enhancing the Activity and Tuning the Mechanism of Formic acid Oxidation at Tetrahexahedral Pt Nanocrystals by Au Decoration. Physical Chemistry Chemical Physics, 14(47), 16415-16423. https://doi.org/10.1039/c2cp42930f

Published in:

Physical Chemistry Chemical Physics

Document Version:

Early version, also known as pre-print

Queen's University Belfast - Research Portal:

Link to publication record in Queen's University Belfast Research Portal

Publisher rights

(c) Royal Society of Chemistry

\section{General rights}

Copyright for the publications made accessible via the Queen's University Belfast Research Portal is retained by the author(s) and / or other copyright owners and it is a condition of accessing these publications that users recognise and abide by the legal requirements associated with these rights.

Take down policy

The Research Portal is Queen's institutional repository that provides access to Queen's research output. Every effort has been made to ensure that content in the Research Portal does not infringe any person's rights, or applicable UK laws. If you discover content in the Research Portal that you believe breaches copyright or violates any law, please contact openaccess@qub.ac.uk. 


\title{
Enhancing the activity and tuning the mechanism of formic acid oxidation at tetrahexahedral Pt nanocrystals by Au decoration $\dagger$
}

\author{
Hai-Xia Liu, ${ }^{a}$ Na Tian, ${ }^{* a}$ Michael P. Brandon, ${ }^{b}$ Jun Pei, ${ }^{a}$ Zhi-Chao Huangfu, ${ }^{a}$ \\ Chi Zhan, ${ }^{a}$ Zhi-You Zhou, ${ }^{a}$ Christopher Hardacre, ${ }^{b}$ Wen-Feng Lin ${ }^{* b}$ and \\ Shi-Gang Sun*a
}

Received 21st August 2012, Accepted 12th October 2012

DOI: $10.1039 / \mathrm{c} 2 \mathrm{cp} 42930 \mathrm{f}$

Tetrahexahedral Pt nanocrystals (THH Pt NCs), bound by high index facets, belong to an emerging class of nanomaterials that promise to bridge the gap between model and practical electrocatalysts. The atomically stepped surfaces of THH Pt NCs are extremely active for the electrooxidation of small organic molecules but they also readily accommodate the dissociative chemisorption of such species, resulting in poisoning by strongly adsorbed CO. Formic acid oxidation is an ideal reaction for studying the balance between these competing catalyst characteristics, since it can proceed by either a direct or a $\mathrm{CO}$ mediated pathway. Herein, we describe electrochemical and in situ FTIR spectroscopic investigations of formic acid electrooxidation at both clean and Au adatom decorated THH Pt NC surfaces. The Au decoration leads to higher catalytic currents and enhanced $\mathrm{CO}_{2}$ production in the low potential range. As the $\mathrm{CO}$ oxidation behaviour of the catalyst is not improved by the presence of the $\mathrm{Au}$, it is likely that the role of the Au is to promote the direct pathway. Beyond their fundamental importance, these results are significant in the development of stable, poison resistant anodic electrocatalysts for direct formic acid fuel cells.

\section{Introduction}

Broadly speaking, over the last 30 years, research on electrocatalysis has following two distinct, if parallel, paths. One approach has been the systematic study of adsorption and reaction phenomena at the well-defined model catalyst surfaces provided by single crystal electrodes. Conversely, work has continued on less structurally certain materials such as polycrystalline electrodes, electrodeposits and supported nanoparticles, since these systems are more immediately applicable to the current generation of practical electrocatalysts. Recent advances in the preparation of shaped nanoparticles, bound by well characterised surfaces, ${ }^{1-5}$ have marked the opening of a third front in the quest for optimal catalyst design. ${ }^{6,7}$ These materials offer the prospect of convergence between the different strands of electrocatalytic research,

${ }^{a}$ State Key Lab of Physical Chemistry of Solid Surfaces,

Department of Chemistry, College of Chemistry and Chemical

Engineering, Xiamen University, Xiamen 361005, China.

E-mail:tnsd@xmu.edu.cn,sgsun@xmu.edu.cn;

Fax: + 86592 2183047; Tel: + 865922180181

${ }^{b}$ Centre for the Theory and Application of Catalysis (CenTACat), School of Chemistry and Chemical Engineering, Queen's University Belfast, Belfast BT9 5AG,UK. E-mail: w.lin@qub.ac.uk;

Fax: + 44 (0)289097 6524; Tel: + 44 (0)28 90974175

$\dagger$ Electronic supplementary information (ESI) available. See DOI: $10.1039 / \mathrm{c} 2 \mathrm{cp} 42930 \mathrm{f}$ with the possibility of the transfer of knowledge from single crystal studies to practical applications. ${ }^{8-10}$

Formic acid oxidation on platinum electrodes has come to be considered as a model anodic reaction in electrocatalysis, owing to its relative straightforwardness compared with the electrooxidation of other small organic molecules (SOMs). ${ }^{11,12}$ Interest in this reaction is not, however, confined to fundamental science, with much recent research into the development of direct formic acid fuel cells (DFAFCs). The DFAFC has a number of advantages compared to the more established direct methanol fuel cell (DMFC) technology. These include a higher theoretical open circuit voltage, reduced fuel crossover through the polymer membrane and enhanced proton transport in the catalyst layer, since formic acid is, of itself, a strong electrolyte. ${ }^{13}$ In addition, formic acid is considerably less toxic than methanol and is, therefore, considered suitable for small portable fuel cells. ${ }^{13}$ Pd based anodes have exhibited superior short term formic acid electrooxidation performance compared with Pt catalysts, however, the former are less stable under realistic fuel cell conditions and are prone to non-CO poisoning. ${ }^{13,14}$ Hence, the commercialisation of DFAFCs faces a challenge common to all direct alcohol fuel cells, namely, the need to reduce the loading of expensive Pt by optimising catalyst composition and structure. ${ }^{8,15}$

It has long been established that formic acid electrooxidation at Pt proceeds by two parallel pathways. ${ }^{16}$ The direct path 
is a relatively facile process, ${ }^{17}$ involving the formation of $\mathrm{CO}_{2}$, by dehydrogenation through $\mathrm{HCOO}$ as the reactive intermediate. ${ }^{18}$ The much slower indirect route consists of the dehydration of $\mathrm{HCOOH}$, through a surface blocking and poisoning intermediate, most commonly identified as adsorbed carbon monoxide $\left(\mathrm{CO}_{\mathrm{ads}}\right){ }^{18,19}$ Since the latter species can only be oxidised (on pure $\mathrm{Pt}$ ) at potentials above ca. $0.6 \mathrm{~V}$ (vs. RHE), it is imperative for fuel cell applications to direct the overall reaction onto the dehydrogenation pathway, in order to achieve cell efficiency at low potentials and avoid catalyst poisoning. ${ }^{13}$

Numerous studies with Pt single crystal electrodes (both basal plane and stepped surfaces) have revealed formic acid electrooxidation to be a highly surface sensitive reaction. ${ }^{17,20-27}$ Owing to the self-poisoning nature of the dehydration reaction, it can be difficult to decouple intrinsic activity from poisoning effects. Work by our group ${ }^{23}$ established an intrinsic, surface specific, reactivity series of $\operatorname{Pt}(110)>\operatorname{Pt}(111)>\operatorname{Pt}(100)$. In contrast, Feliu and co-workers proposed that Pt surfaces of (100) character are the most active towards $\mathrm{HCOOH}$ oxidation, but also the most prone to poisoning. ${ }^{20,22}$ There is a general consensus that while $\mathrm{CO}_{\text {ads }}$ poisoning is minimised on $\mathrm{Pt}(111)$, the overall reaction rate is also moderate for this surface. ${ }^{17,20,21,25}$

In 2007 we reported the preparation of tetrahexahedral $\mathrm{Pt}$ nanocrystals (THH Pt NCs) bound by well-defined high index facets. ${ }^{28}$ The tetrahexahedral shape may be represented as a cube with a square based pyramid on each of the six faces, leading to a polyhedron with 24 facets. Analysis by transmission electron microscopy revealed that the crystals were bound mainly by $\{730\}$ planes. ${ }^{1,8}$ Owing to the high density of surface atoms at step and kink sites, such open facets of Pt are expected to be particularly catalytically active for bond cleavage in the oxidation of SOMs. ${ }^{29}$ This proved to be the case for formic acid electrooxidation, with THH Pt NCs exhibiting potential dependent current enhancements of between two and three-fold, relative to a commercial $\mathrm{Pt} / \mathrm{C}$ catalyst. ${ }^{28}$ As the more open faces are prone to $\mathrm{CO}$ poisoning, it is likely that considerable self-poisoning is operative on the $\{730\}$ surfaces. This point was confirmed by more recent experiments. ${ }^{30}$ Therefore, in order to fully optimise the already impressive catalytic performance of the THH Pt NCs, it is necessary to devise a strategy to reduce, as far as possible, the formation of $\mathrm{CO}_{\mathrm{ads}}$ during formic acid oxidation.

A common solution to this problem is the introduction of atoms of other transition metals into/onto the catalytic surface, either by alloying or irreversible adsorption. ${ }^{13,31}$ The metal atoms that have been incorporated into Pt electrode surfaces for formic acid electrooxidation studies include $\mathrm{Pd},{ }^{32-37} \mathrm{Bi}^{30,38-40} \mathrm{~Pb},{ }^{39,41}$ and $\mathrm{Ru} .{ }^{35,42}$ Owing to its unrivalled stability, $\mathrm{Pt}-\mathrm{Au}$ bimetallic systems have recently received much attention. ${ }^{43}$ The literature contains reports on formic acid electrooxidation at $\mathrm{Pt} / \mathrm{Au}$ alloys, ${ }^{11,42,44-49}$, co-deposits, ${ }^{50}$ as well as Pt decorated Au electrodes. ${ }^{11,43,50-54}$ In contrast, little attention has been devoted to the reaction at Au-decorated $\mathrm{Pt}$ surfaces - work on this configuration is confined to either polycrystalline $\mathrm{Pt}$ macro electrodes ${ }^{43}$ or $\mathrm{Au}$ on $\mathrm{Pt}$ thin films. ${ }^{14,50}$ To the best of our knowledge, there have been no studies on the formic acid oxidation reaction at well-defined $\mathrm{Pt}$ crystal planes decorated by $\mathrm{Au}$. In the present report, we rectify this situation, by adsorbing sub-monolayer of $\mathrm{Au}$ onto the high index facets of THH Pt NCs and evaluating the effect of these modifications on the formic acid electrooxidation performance. This study is complementary to our recently reported work, on the same reaction, at $\mathrm{Bi}$ decorated $\mathrm{THH} \mathrm{Pt}$ $\mathrm{NC}$ electrodes, ${ }^{30}$ however, the analysis, herein, is extended by introducing in situ FTIR spectroscopy in addition to conventional electrochemical measurements.

\section{Experimental section}

\subsection{Materials and electrochemical setup}

Formic acid (A.R. reagent), $\mathrm{CuSO}_{4} \cdot 5 \mathrm{H}_{2} \mathrm{O}$ (A.R. reagent) and $\mathrm{HAuCl}_{4} \cdot x \mathrm{H}_{2} \mathrm{O}$ (pure) were purchased from China Medicine Shanghai Chemical Reagent Corp. Other reagents were: $\mathrm{K}_{2} \mathrm{PtCl}_{6}(99.99 \%$, Sigma Aldrich), ascorbic acid (99\%, Alfa Aesar), sulfuric acid (96\%, Merck) and CO (99.99\%, Xiamen, Xinhang Co.). All solutions were prepared using water treated by a Milli-Q lab system (resistivity $=18.2 \mathrm{M} \Omega \mathrm{cm}$ ).

The electrochemical experiments were conducted with a PAR 263A potentiostat/galvanostat controlled by in house software. A conventional three electrode cell was used and all measurements were performed at room temperature $\left(\sim 25^{\circ} \mathrm{C}\right)$. A glassy carbon (GC) working electrode $(\Phi=6 \mathrm{~mm})$ was used as the substrate for the deposition of the THH Pt NCs. Prior to use, it was mechanically polished by successively using alumina powder of sizes 5,1 , and $0.3 \mu \mathrm{m}$, and then cleaned in an ultrasonic bath. A saturated calomel electrode (SCE) was employed as the reference and all potentials are quoted relative to this scale. The counter electrode was formed by a Pt foil. All solutions were de-aerated by a flow of pure $\mathrm{N}_{2}$ gas $(99.99 \%)$ for $15 \mathrm{~min}$ before the experiments.

\subsection{Deposition of THH Pt NCs}

The detailed method for the preparation of THH Pt NCs has been reported elsewhere. ${ }^{28}$ Briefly, the first step involves the deposition of $\mathrm{Pt}$ nuclei onto the GC surface from a solution of $2 \mathrm{mM} \mathrm{K}_{2} \mathrm{PtCl}_{6}+0.5 \mathrm{M} \mathrm{H}_{2} \mathrm{SO}_{4}$, by applying a potential step from 1.20 to $-0.25 \mathrm{~V}$ and holding for $20 \mathrm{~ms}$. Polycrystalline $\mathrm{Pt}$ nanospheres were then formed at the nucleation sites by subjecting the working electrode to a $100 \mathrm{~Hz}$ square wave potential program between 0.23 and $0.60 \mathrm{~V}$ for $30 \mathrm{~min}$. Finally, by applying a square wave potential $(-0.20$ to $1.20 \mathrm{~V})$ of $10 \mathrm{~Hz}$ frequency in $30 \mathrm{mM}$ ascorbic acid $+0.1 \mathrm{M} \mathrm{H}_{2} \mathrm{SO}_{4}$ solution for $30 \mathrm{~min}$, the nanospheres were progressively dissolved and re-deposited in the form of a sub-monolayer of single crystal THH NCs. The Miller indices are determined to be about $\{730\}$ for the THH Pt NCs prepared by this method (Fig. S1, ESI $\dagger)$. Characterization was conducted by cyclic voltammetry in $0.1 \mathrm{M} \mathrm{H}_{2} \mathrm{SO}_{4}$ solution and by scanning electron microscopy (SEM, Hitachi S-4800).

\subsection{Surface decoration of THH Pt NCs by Au}

The gold decoration was accomplished through the initial underpotential deposition (UPD) of a sub-monolayer of $\mathrm{Cu}$ atop the THH Pt surfaces, followed by the exchange of the $\mathrm{Cu}$ for $\mathrm{Au}$ adatoms by galvanic replacement. ${ }^{14}$ This method is 


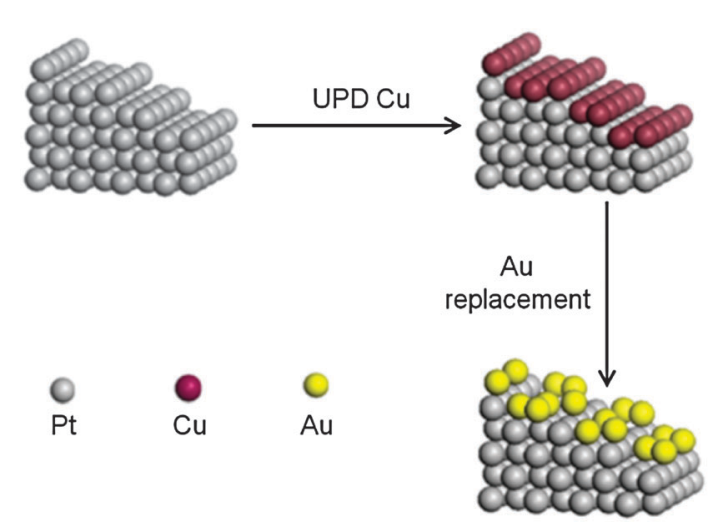

Scheme 1 The procedure for depositing Au adatoms on the THH Pt surface.

also fit for carbon-supported Pt catalysts. ${ }^{55}$ The strategy is presented schematically in Scheme 1. For the lowest coverage, the $\mathrm{Cu}$ adlayer was deposited by applying a potential of $0.50 \mathrm{~V}$ for $50 \mathrm{~s}$ in $0.1 \mathrm{mM} \mathrm{CuSO}_{4}+0.1 \mathrm{M} \mathrm{H}_{2} \mathrm{SO}_{4}$ solution. The galvanic replacement reaction was performed by inserting the working electrode in dilute aqueous $\mathrm{HAuCl}_{4}$ solution for approximately $1 \mathrm{~min}$. The electrode was then subjected to potential cycling between -0.24 and $1.20 \mathrm{~V}$ in $0.1 \mathrm{M} \mathrm{H}_{2} \mathrm{SO}_{4}$. The possible residual $\mathrm{Cu}$ atoms on the surfaces could be removed completely. The coverage of Au was determined by comparing the hydrogen adsorption/desorption charge before and after $\mathrm{Au}$ decoration. The Au adatom coverage was varied by changing the time of the initial $\mathrm{Cu}$ deposition process.

\subsection{Electro-oxidation studies}

For each Au coverage, following voltammetric characterisation, the electrode was transferred to a cell containing $0.25 \mathrm{M}$ $\mathrm{HCOOH}+0.1 \mathrm{M} \mathrm{H}_{2} \mathrm{SO}_{4}$. The electrocatalytic activity for formic acid oxidation was quantified, firstly by cyclic voltammetry $\left(-0.24 \rightarrow 0.75 \mathrm{~V}, 50 \mathrm{mV} \mathrm{s}^{-1}\right)$, and then by chronoamperometry. The potential was held at $1.20 \mathrm{~V}$ for $5 \mathrm{~s}$ to oxidize absorbed intermediates and clean the electrode surface. Next, the electrode was polarized for $0.3 \mathrm{~s}$ at $-0.24 \mathrm{~V}$ to reduce the oxides, and then it was polarized for $600 \mathrm{~s}$ at the study potential. The initial study potential was $0.05 \mathrm{~V}$ and the foregoing procedure was repeated for test potentials at $50 \mathrm{mV}$ intervals up to $0.20 \mathrm{~V}$. The current density at $-0.15 \mathrm{~V}$ was set as the background current as for the trace of dissolved oxygen reduction in the solution.

The dependence of $\mathrm{CO}$ oxidation performance on $\mathrm{Au}$ surface coverage was studied by anodic stripping voltammetry in $0.1 \mathrm{M} \mathrm{H}_{2} \mathrm{SO}_{4}$ solutions. In this case, the $\mathrm{THH} \mathrm{Pt} \mathrm{NCs}$ electrode (or Au-decorated THH Pt NCs electrode) was placed into $0.1 \mathrm{M} \mathrm{H}_{2} \mathrm{SO}_{4}$ solution. $\mathrm{CO}$ gas was then bubbled through the solution for $15 \mathrm{~min}$, with the electrode potential held at $-0.10 \mathrm{~V}$, in order to ensure complete surface coverage by adsorbed CO. The CO supply was then turned off and in its place $\mathrm{N}_{2}$ gas was bubbled for 20 min to purge the solution of $\mathrm{CO}$. At all times, the potential was maintained at $-0.10 \mathrm{~V}$ to preserve the $\mathrm{CO}_{\mathrm{ads}}$ monolayer on the surface of the $\mathrm{THH}$ Pt NCs (or Au-decorated THH Pt NCs). Finally, the CO oxidation behaviour was investigated by performing a $\mathrm{CV}$ measurement, starting from an initial potential of $-0.10 \mathrm{~V}$, sweeping down to $-0.24 \mathrm{~V}$ and then completing a cycle with an upper limit of $0.65 \mathrm{~V}$. The scan rate was $50 \mathrm{mV} \mathrm{s}^{-1}$.

\subsection{In situ FTIR spectroscopy}

The FTIR instrument was a Nicolet Nexus 870 FTIR spectrometer with a liquid-nitrogen-cooled MCT-A detector. A thin layer spectroelectrochemical cell with an IR transparent $\mathrm{CaF}_{2}$ window was utilized, as described elsewhere. ${ }^{56}$ The spectra were the average of 400 interferograms, with a collection resolution of $8 \mathrm{~cm}^{-1}$. The reference spectrum was recorded at $-0.25 \mathrm{~V}$ and the sample spectra were collected after successive $50 \mathrm{mV}$ potential steps in the positive potential direction from -0.20 to $0.30 \mathrm{~V}$. The spectra are presented as the relative change in reflectivity, i.e.,

$$
\frac{\Delta R}{R}\left(E_{\mathrm{S}}\right)=\frac{R\left(E_{\mathrm{S}}\right)-R\left(E_{\mathrm{R}}\right)}{R\left(E_{\mathrm{R}}\right)}
$$

where $R\left(E_{\mathrm{S}}\right)$ and $R\left(E_{\mathrm{R}}\right)$ are the single-beam spectra measured at the sample potential $E_{\mathrm{S}}$ and reference potential $E_{\mathrm{R}}$. Negative bands, therefore, imply the production of species at a given potential; conversely, positive bands indicate the consumption of a substance.

To further probe the effect of Au decoration on the reaction mechanism, time resolved FTIR spectra were also collected at $0.10 \mathrm{~V}$, with the reference spectra acquired at $-0.25 \mathrm{~V}$. These spectra had a resolution of $16 \mathrm{~cm}^{-1}$ and were the average of 32 interferograms.

\section{Results and discussion}

\subsection{Au modification of THH Pt NCs}

A representative scanning electron micrograph of the as-prepared $\mathrm{Pt}$ nanoparticles is presented in Fig. 1A. These crystals have a mean diameter of $55 \pm 14 \mathrm{~nm}$ shown in Fig. 1A (inset), with the characteristic THH shape evident in the higher resolution inset. The variation, with $\mathrm{Au}$ coverage, of the voltammetric profile of the THH Pt NC electrode is shown in Fig. 1B. The CV of the unmodified electrode exhibits various features that are characteristic of $\mathrm{THH} \mathrm{Pt} \mathrm{NCs,} \mathrm{as}$ was recently discussed in detail. ${ }^{30}$ Particularly noteworthy is the pronounced oxygen adsorption peak present in the anodic sweep between 0.50 and $0.65 \mathrm{~V}$. This peak, conspicuously absent from the $\mathrm{CV}$ of the polycrystalline $\mathrm{Pt}$ nanosphere precursor material, arises from oxygen adsorption at step sites on high index facets. ${ }^{28}$ As the coverage is increased there is a progressive diminishment of the charge associated with hydrogen adsorption/desorption peaks at -0.02 and $-0.16 \mathrm{~V}$, owing to the blockage of $\mathrm{Pt}$ surface sites by $\mathrm{Au}$ adatoms. The same explanation accounts for the decline in $\mathrm{Pt}$ oxide formation (above $0.46 \mathrm{~V}$ ) and reduction ( $c a .0 .30-0.75 \mathrm{~V}$ ) currents. Increasing the upper voltammetric limit to $1.2 \mathrm{~V}$ resulted in peaks associated with Au oxidation (1.0-1.2 V) and reduction $(0.75-1.0 \mathrm{~V})$ which can be clearly seen in the electrode of $\mathrm{Au}$ decorated THH Pt NCs, as shown in Fig. 1C. The reductive peak of $\mathrm{Au}$ oxide at about $0.90 \mathrm{~V}$ provides reliable evidence for the existing of Au atoms on the Pt surfaces.

Since hydrogen adsorption on $\mathrm{Au}$ is negligible in the potential region under consideration, ${ }^{57}$ the exposed Pt surface 

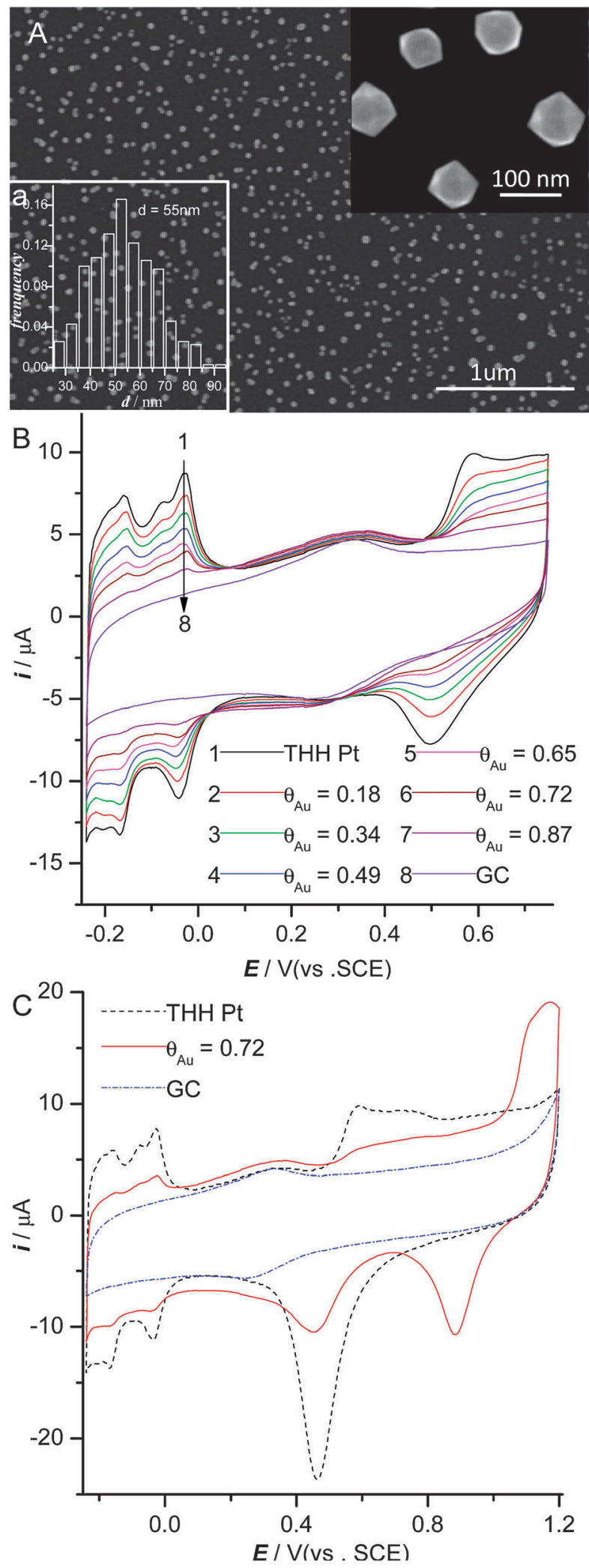

Fig. 1 (A) SEM image of the THH Pt NCs used in the present study. The characteristic THH shape is obvious in the higher magnification inset. (a) Size distribution data for the THH Pt NCs. (B) Cyclic voltammograms of THH Pt NCs decorated by various coverages of $\mathrm{Au}$ adatoms recorded in $0.1 \mathrm{M} \mathrm{H}_{2} \mathrm{SO}_{4}$ solution at $50 \mathrm{mV} \mathrm{s}^{-1}$. (C) $\mathrm{CVs}$ recorded at higher potential to show the redox of $\mathrm{Au}$. For comparison, CVs of THH Pt NCs and the bare GC electrode were also shown. area for each decorated surface can be determined by the standard approach of normalising the hydrogen adsorption/ desorption charge (the integrated charge of hydrogen adsorption/ desorption between $-0.24-0.05 \mathrm{~V}$ in the CVs shown in Fig. 1B) to the theoretical monolayer value of $210 \mu \mathrm{C} \mathrm{cm}{ }^{-2}{ }^{58}$ This in turn facilitates the calculation of a readily accessible, experimental measure of gold fractional coverage, $\theta_{\mathrm{Au}}$, defined as:

$$
\theta_{\mathrm{Au}}=1-\theta_{\mathrm{H}}=1-\frac{Q_{\mathrm{H}}^{\mathrm{Au}}}{Q_{\mathrm{H}}^{\mathrm{unm}}}
$$

Here $Q_{\mathrm{H}}^{\mathrm{Au}}$ is the charge for hydrogen adsorption on the Au-decorated THH Pt NCs, while $Q_{\mathrm{H}}^{\mathrm{unm}}$ is the charge for hydrogen adsorption on bare THH Pt NCs. As was discussed elsewhere ${ }^{59}$ for the electrodeposition of $\mathrm{Ru}$ adatoms onto the $\mathrm{Pt}\{730\}$ surface, the fractional coverage as defined here is likely to be higher than the true extent of monolayer coverage of $\mathrm{Au}$ adatoms. It must be considered, for example, that an isolated $\mathrm{Au}$ atom occupying a 4-fold (110) site on the step edge will block four hydrogen adsorption sites, while the number of blocked sites drops to an average of two per step-site adatom for full Au decoration of the step edge. Indeed, Au adsorption through the displacement of pre-adsorbed $\mathrm{Cu}$ atoms presents a more complicated situation than the direct electrodeposition of Ru adatoms, since it not only involves two steps, but it must be remembered that two $\mathrm{Au}$ atoms replace every three $\mathrm{Cu}$ atoms according to the reaction:

$$
3 \mathrm{Cu}+2 \mathrm{AuCl}_{4}^{-} \rightarrow 2 \mathrm{Au}+3 \mathrm{Cu}^{2+}+8 \mathrm{Cl}^{-}
$$

Therefore rearrangement of the Au adatoms subsequent to the galvanic replacement in order to attain the most thermodynamically favorable configuration may occur. TEM characterization (Fig. S2 and S3, ESI $\dagger$ ) indicates that besides mono-atomic $\mathrm{Au}$ adlayers, there are also a few $\mathrm{Au}$ clusters on Pt surfaces.

\subsection{Formic acid electrooxidation}

Fig. 2A features the forward segments of cyclic voltammograms recorded for clean, and various $\mathrm{Au}$ decorated $\mathrm{THH} \mathrm{Pt}$ $\mathrm{NC}$ electrodes in $0.25 \mathrm{M} \mathrm{HCOOH}+0.1 \mathrm{M} \mathrm{H}_{2} \mathrm{SO}_{4}$. All of the current densities are calculated by normalization of original current to the ECSA of the bare THH Pt NCs (i.e., before modification). The voltammetric profile for the unmodified electrode is typical of those previously presented and discussed in the literature for formic acid electrooxidation on pure Pt. ${ }^{11,16,43}$ A catalytic current for the oxidation of $\mathrm{HCOOH}$ via the direct pathway has an onset just above the hydrogen region and it rises with potential up to $\sim 0.25 \mathrm{~V}$ (Peak I). ${ }^{60}$ $\mathrm{CO}_{\mathrm{ads}}$ adsorption occurs in parallel to the dehydrogenation reaction and its increasing coverage limits the number of sites available to the direct reaction, causing an arrest in the current above $0.25 \mathrm{~V}$. The current increases again beyond $\sim 0.45 \mathrm{~V}$ owing to the oxidative removal of $\mathrm{CO}_{\mathrm{ads}}$ by oxygenated species which begin to adsorb on $\mathrm{Pt}$ in this potential range. A peak is observed just above $0.61 \mathrm{~V}$ (Peak II) with the current decreasing at higher potentials due to oxide formation on the Pt surface. ${ }^{43}$ According to this analysis, the ratio of the charge associated with Peak I compared with Peak II is an indication of the extent of the direct path relative to the indirect path for a given electrocatalyst. 


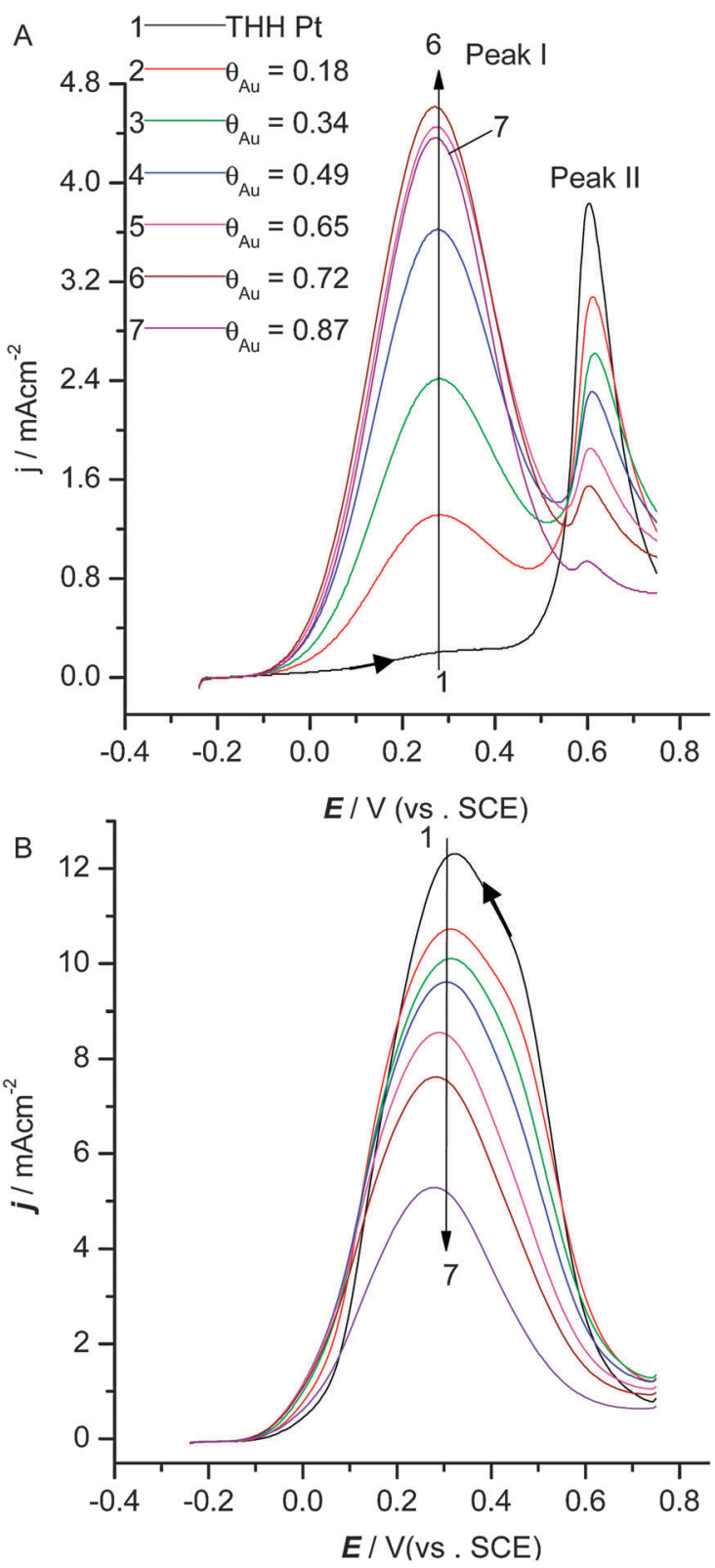

Fig. 2 (A) Forward segments of $\mathrm{CVs}$ characterising formic acid electrooxidation on THH Pt NC electrodes with different Au coverages. (B) Backward segments of $\mathrm{CVs}$ characterising formic acid on various electrodes. The test solution was $0.25 \mathrm{M} \mathrm{HCOOH}+0.1 \mathrm{M} \mathrm{H}_{2} \mathrm{SO}_{4}$ and the scan rate was $50 \mathrm{mV} \mathrm{s}^{-1}$.

Fig. 2B presents the backward segments of cyclic voltammograms. The liberation of the active Pt sites from $\mathrm{CO}_{\mathrm{ads}}$ at the upper end of the forward sweep permits formic acid oxidation to occur at a much greater rate, and predominantly by the direct pathway, on the backward scan. Previously, Osawa and co-workers ${ }^{61}$ used electrochemical in situ time-resolved FTIR spectroscopy to simultaneously trace the IR band of $\mathrm{CO}$ and current of $\mathrm{HCOOH}$ oxidation on Pt electrode, and found that in the forward scan, high-coverage $\mathrm{CO}$ occupied Pt surfaces before Peak II, and quickly disappeared during Peak II; in the backward scan, $\mathrm{CO}$ appeared again at the tail $(<0.10 \mathrm{~V})$ of the broad current peak. This result provided a clear evidence of $\mathrm{CO}$ poisoning for $\mathrm{HCOOH}$ oxidation. In our work, the observed peak current density was $12.3 \mathrm{~mA} \mathrm{~cm}^{-2}$ at $0.32 \mathrm{~V}$ on the backward scan, compared with only $0.23 \mathrm{~mA} \mathrm{~cm}{ }^{-2}$ for the plateau on the forward scan on the clean THH Pt NCs. It shows that the $\mathrm{Pt}\{730\}$ surface is prone to $\mathrm{CO}$ poisoning during $\mathrm{HCOOH}$ electrooxidation.

The introduction of Au adatoms onto the stepped Pt surface has a profound effect on the voltammetric profiles for formic acid electrooxidation (Fig. 2). For clarity, Fig. 2A shows the forward potential scan and Fig. 2B shows the backward scan. It can be seen from Fig. 2A, with the increase of Au coverage the current associated with Peak I enhances at the expense of Peak II as the surface becomes progressively more selective towards the direct pathway. Accordingly, the decorated electrodes offer higher activities at lower potentials. In the case of $\theta_{\mathrm{Au}}=$ 0.72 , the peak current density of $4.6 \mathrm{~mA} \mathrm{~cm}^{-2}$ at $0.28 \mathrm{~V}$ is 20 times greater than the plateau current density for the clean electrode. The activity decreases for $\theta_{\mathrm{Au}}>0.72$, since above this threshold, the promoting effect of the Au atoms is beginning to be offset by the loss of active Pt catalytic centers. The peak potential of Peak I and Peak II is almost unaltered at different $\theta_{\mathrm{Au}}$, indicating that the promoting effect of the $\mathrm{Au}$ atoms may not be due to the bifunctional mechanism. In this mechanism, for example as found in $\mathrm{Ru}$ decorated $\mathrm{THH} \mathrm{Pt}$ $\mathrm{NCs},{ }^{59}$ the onset potentials for methanol oxidation were incrementally shifted to lower potentials as the $\mathrm{Ru}$ adatom coverage was increased. Fig. 2B shows the backward potential scan of the Au-decorated $\mathrm{THH} \mathrm{Pt} \mathrm{NCs}$ for formic acid electrooxidation. In this case, the $\mathrm{HCOOH}$ oxidation is free from $\mathrm{CO}$ poisoning, and the observed activity presents intrinsic catalytic activity of clean surfaces. The peak current decreases with the increase in $\theta_{\mathrm{Au}}$, demonstrating that (1) the intrinsic catalytic activity of Au-decorated $\mathrm{THH} \mathrm{Pt}$ NCs is inferior to the bare surface, and (2) the increase in Peak I in Fig. $2 \mathrm{~A}$ is due to the third body effect, i.e., reducing $\mathrm{CO}$ poisoning by foreign adatoms. This is based on the fact that $\mathrm{CO}_{\mathrm{ads}}$ formation via $\mathrm{HCOOH}$ dehydration requires, at a very minimum, three adjacent $\mathrm{Pt}$ sites. ${ }^{62}$ Geometric hindrance by irreversibly adsorbed foreign adatoms can thus inhibit $\mathrm{CO}$ poisoning. ${ }^{63}$ In addition, the optimal Au coverage of 0.72 is also consistent with literature results based on third body effect. For example, Feliu's group has reported that the optimal coverage for formic oxidation is about 0.70 by both simulation and experiment of Bi-decorated $\mathrm{Pt}$ surfaces. $^{12}$

While these potentiodynamic data provide a useful overview of the alleviation of $\mathrm{CO}_{\text {ads }}$ poisoning by $\mathrm{Au}$ adatoms, of more direct relevance to fuel cell applications are potentiostatic measurements in the low potential range $(<c a .0 .25 \mathrm{~V} v s$. SCE). Chronoamperometry measurements were, therefore, conducted for formic acid oxidation at potentials of 0.05 , $0.10,0.15$, and $0.20 \mathrm{~V}$ on both clean and Au-decorated $\mathrm{THH}$ Pt NC electrodes. Current-density transient $(j-t)$ curves recorded at $0.15 \mathrm{~V}$ are presented in Fig. 3A. The chronoamperometry data are summarised in Fig. 3B by plotting the current densities which has been subtracted by the background current at $-0.15 \mathrm{~V}$, as for the trace of dissolved oxygen reduction in the solution, after $600 \mathrm{~s}$ polarisation against applied potential $E$, for each value of $\theta_{\mathrm{Au}}$ studied. The trends in chronoamperometry largely reflect those observed in cyclic 

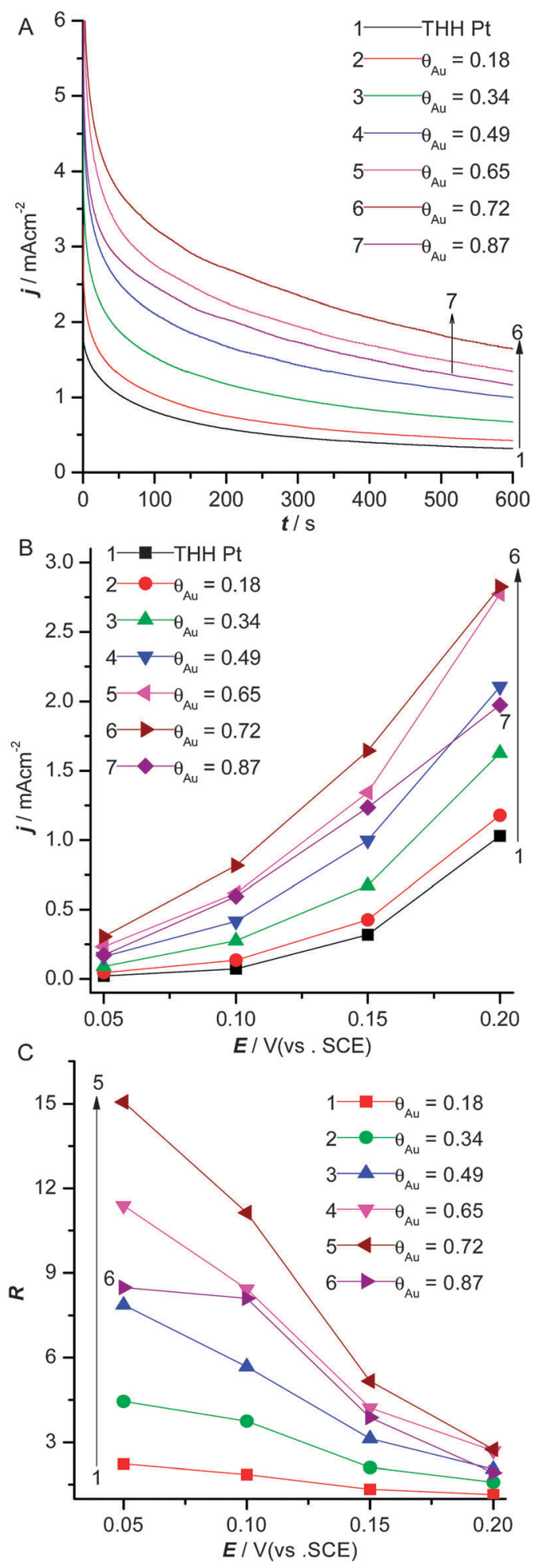

Fig. 3 (A) Current density transient $(j-t)$ curves recorded at $0.15 \mathrm{~V}$ of various $\mathrm{Au}$ decorated $\mathrm{THH} \mathrm{Pt} \mathrm{NC}$ electrodes. (B) Chronoamperometric current density recorded after $600 \mathrm{~s}$ in $0.25 \mathrm{M} \mathrm{HCOOH}+0.1 \mathrm{M} \mathrm{H}_{2} \mathrm{SO}_{4}$ solution plotted against polarisation potential for the various $\mathrm{Au}$ decorated THH Pt NC electrodes. (C) Potential dependence of the enhancement factor $R$. For each Au-decorated electrode, $R$ is the ratio of the relevant current density from Fig. $3 \mathrm{~B}$ to the current density for the clean electrode.

voltammetry at $E \leq 0.15 \mathrm{~V}$, the greatest activity is provided by the $\theta_{\mathrm{Au}}=0.72$ electrode, with all the decorated surfaces outperforming the clean THH Pt NCs. To probe the latter point, plots of the enhancement factor, $R$, against potential have been constructed in Fig. 3C.

$R$ is defined as the ratio of the current density measured for $\mathrm{Au}$ decorated THH Pt NCs to that observed for clean $\mathrm{THH} \mathrm{Pt}$ NCs at the same potential. For all adlayer coverage, the value of $R$ diminishes with increasing potential. When $\theta_{\mathrm{Au}}=0.72$, $R$ falls from 15 at $E=0.05 \mathrm{~V}$ to just 2.7 at $E=0.20 \mathrm{~V}$. This suggests that the poisoning effect is more pronounced at the lower potential and is naturally alleviated as the polarization voltage is raised.

The electrochemical stability of pristine and Au-decorated THH Pt NCs is fairly good. After 1000 potential cycles between $0.6 \sim 1.1 \mathrm{~V}$ ( $v s$. RHE), the loss in electroactive surface area is less than 3\% (Fig. S4, ESI $\dagger$ ) for both cases.

\subsection{CO stripping from the Au decorated THH Pt NCs}

The origin of the superior tolerance of the Au decorated THH Pt NC surfaces to $\mathrm{CO}_{\text {ads }}$ poisoning can also be understood by studying the oxidative stripping of the deliberately adsorbed $\mathrm{CO}$ monolayer during anodic voltammetric sweeps. CO stripping voltammograms for THH Pt NC electrodes with various $\theta_{\mathrm{Au}}$ are presented in Fig. 4. It is apparent that the $\mathrm{CO}$ oxidation peak current decreases with increasing $\theta_{\mathrm{Au}}$, while the peak potential remains unaltered.

The unaltered peak potential of $\mathrm{CO}$ oxidation at different $\theta_{\mathrm{Au}}$ demonstrates again that the enhancement effect is not due to a bifunctional mechanism. This is in agreement with the analysis of other workers who have examined Au decoration of $\mathrm{Pt}$ surfaces and have pointed out that the bifunctional mechanism is unlikely for this system since Au is less oxophilic than Pt. ${ }^{11,43}$ The peak current decreases with increasing $\theta_{\mathrm{Au}}$, caused by the reduction in the availability of $\mathrm{Pt}$ sites for the adsorption of $\mathrm{CO}$ molecules, which is in accordance with the improvement of the formic acid electrooxidation through

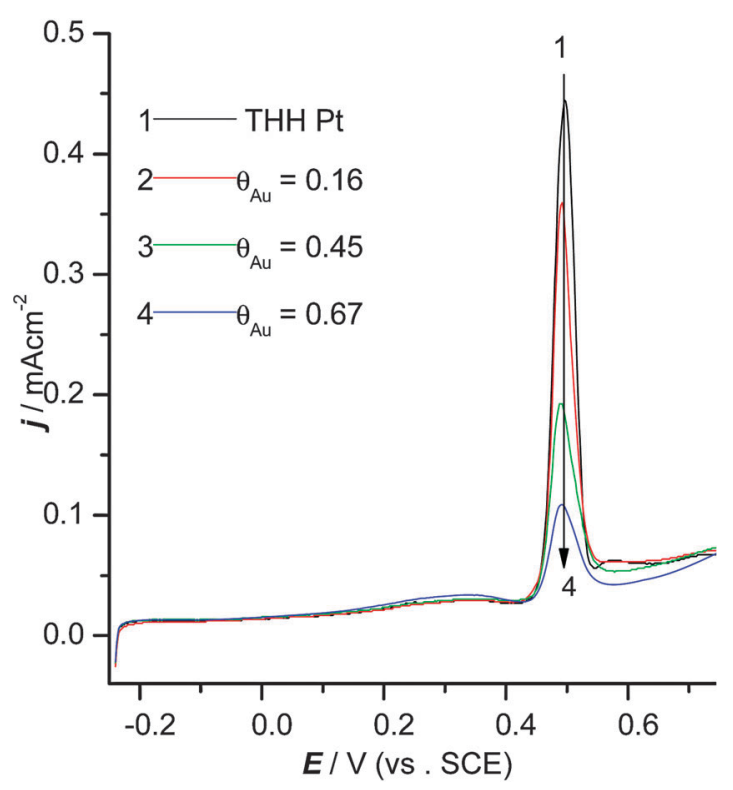

Fig. 4 Anodic CO stripping CVs for clean and $\mathrm{Au}$ decorated THH Pt $\mathrm{NC}$ electrodes. The test solution was $0.1 \mathrm{M} \mathrm{H}_{2} \mathrm{SO}_{4}$ and the scan rate was $50 \mathrm{mV} \mathrm{s}^{-1}$. 
the direct mechanism on the Au-decorated THH Pt NCs in Fig. 2A, i.e., a third body effect.

\subsection{In situ FTIR spectroscopy}

While many important aspects of the electrooxidation of $\mathrm{HCOOH}$ at clean and $\mathrm{Au}$ decorated THH Pt NC surfaces can be inferred from the electrochemical data presented in Sections 3.2 and 3.3, verification of our analysis requires more specific molecular information of the type that can be provided by in situ FTIR measurements of the catalyst/electrolyte interface as the reaction proceeds. FTIR spectra recorded at various potentials in $0.25 \mathrm{M} \mathrm{HCOOH}+0.1 \mathrm{M} \mathrm{H}_{2} \mathrm{SO}_{4}$ solution are presented in Fig. 5A and $\mathrm{B}$ for both clean and $\mathrm{Au}$ decorated $\left(\theta_{\mathrm{Au}}=0.74\right) \mathrm{THH} \mathrm{Pt} \mathrm{NC}$ electrodes. The positive bands at $\sim 1720,1400$ and $1225 \mathrm{~cm}^{-1}$ arise from the consumption of formic acid and correspond to the $\mathrm{C}=\mathrm{O}$ stretching mode of solution phase $\mathrm{HCOOH}{ }^{64,65}$ The negative band at $2341 \mathrm{~cm}^{-1}$ can be ascribed to the formation of $\mathrm{CO}_{2}{ }^{65}$ Linearly bonded $\mathrm{CO}\left(\mathrm{CO}_{\mathrm{L}}\right)$, adsorbed on $\mathrm{Pt}$, gives rise to the band observed at $\sim 2070 \mathrm{~cm}^{-1}$. ${ }^{65,66}$ The bipolar appearance of the latter feature is due to a potential dependent shift in IR absorption frequency (Stark effect), which in turn indicates the presence of $\mathrm{CO}_{\mathrm{L}}$ at both the sampling and reference potentials. This implies that dissociative adsorption of formic acid to form $\mathrm{CO}_{\mathrm{L}}$ occurs by the displacement of adsorbed $\mathrm{H}$ atoms from THH Pt NCs surfaces even at very low potentials $(-0.25 \mathrm{~V})$. The detection of $\mathrm{CO}_{\mathrm{L}}$ also verifies the $\mathrm{CO}$ poisoning for formic acid oxidation on Pt.

The effect of Au decoration on the catalytic performance of the THH Pt NCs is most obvious when comparing the $\mathrm{CO}_{\mathrm{L}}$ (around $2070 \mathrm{~cm}^{-1}$, the poison species) and the $\mathrm{CO}_{2}\left(2341 \mathrm{~cm}^{-1}\right.$, the oxidation product) signals for the clean and decorated surfaces. In Fig. 5A and B (as shown in the insets in Fig. 5A and $\mathrm{B}$, respectively), the IR band of the $\mathrm{CO}_{\mathrm{L}}$ was significantly weaker on $\mathrm{Au}$ decorated $\mathrm{THH} \mathrm{Pt} \mathrm{NCs}$ than that on the unmodified sample. For THH Pt NCs electrode, the $\mathrm{CO}_{2}$ IR band first becomes evident at $E=-0.15 \mathrm{~V}$, and for the Au-decorated one the $\mathrm{CO}_{2}$ band was clear at $E=-0.2 \mathrm{~V}$. In addition, the intensity of the $\mathrm{CO}_{2}$ band is much larger over the entire range of potentials studied for the Au-decorated THH Pt NCs. In this regard there is close agreement between the in situ FTIR measurements and the electrochemical activity data described in Section 3.2, with the Au-decorated anodes yielding enhanced products of $\mathrm{CO}_{2}$ in the former and enhanced oxidation currents in the latter. We place these FTIR data on a quantitative footing in Fig. 5C by plotting the integrated intensity of the $\mathrm{CO}_{2}\left(2341 \mathrm{~cm}^{-1}\right)$ band against sampling potential for the two electrodes (they had nearly the same active surface area). From this plot it is evident that the Au decorated surface is a much more efficient catalyst for $\mathrm{CO}_{2}$ production compared with the as-produced Pt NCs for $E \leq 0.30 \mathrm{~V}$ (e.g. at $E=0.20 \mathrm{~V})$. Au modification achieves a seven-fold increase in the integrated intensity of the $\mathrm{CO}_{2}$ band. The intensity of the $\mathrm{CO}_{\mathrm{L}}$ band from the bipolar peaks of $\mathrm{CO}_{\mathrm{L}}$ in Fig. 5A and $\mathrm{B}$ is shown in Fig. 5D. We can see that the Au-decorated THH Pt electrode depressed the adsorbed $\mathrm{CO}$ formation on the surface of the Pt.

Since the CO stripping experiments (Section 3.3) indicated that $\mathrm{Au}$ decoration does not lower the oxidation onset
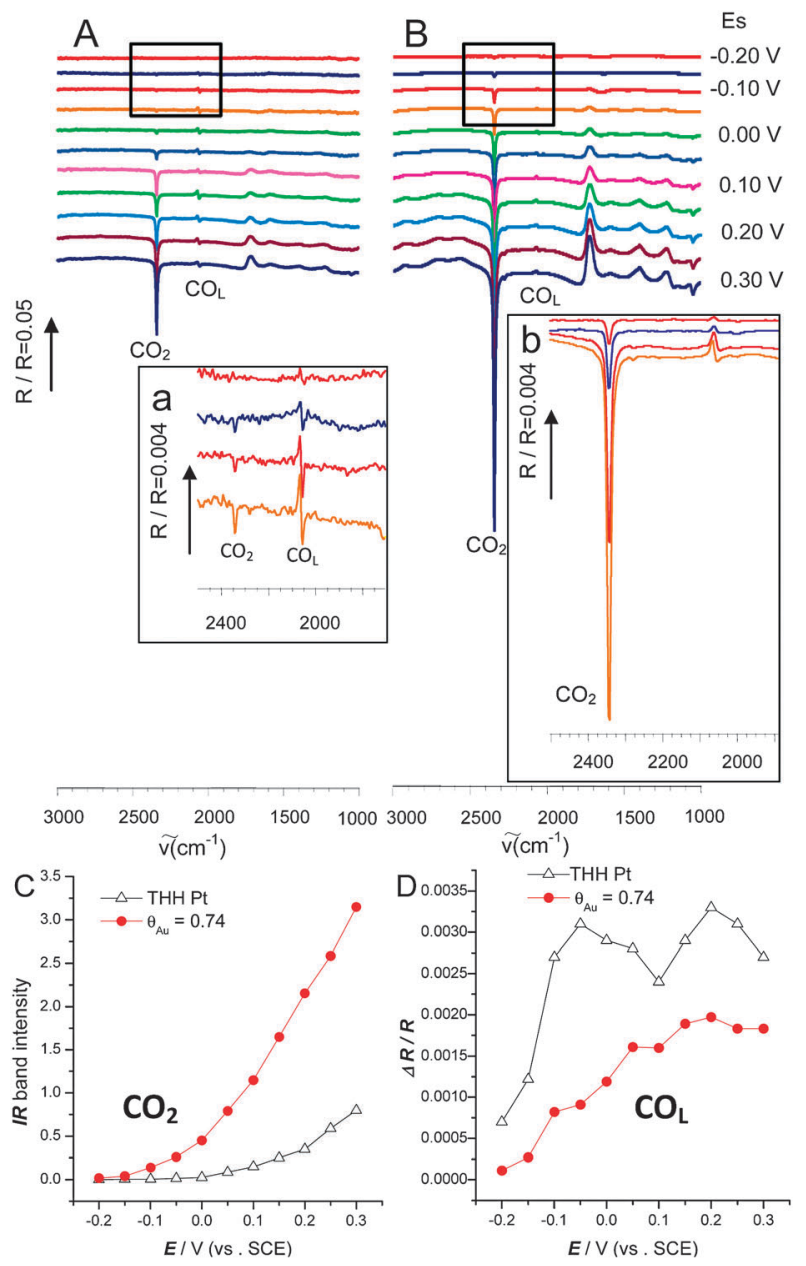

Fig. 5 In situ FTIR spectra for formic acid electrooxidation in $0.25 \mathrm{M} \mathrm{HCOOH}+0.1 \mathrm{M} \mathrm{H}_{2} \mathrm{SO}_{4}$ solution on (A) a clean THH Pt $\mathrm{NC}$ electrode, and (B) the same electrode with $\theta_{\mathrm{Au}}=0.74$. The reference spectra were recorded at $E_{\mathrm{R}}=-0.25 \mathrm{~V}$. (C) Variation of intensity $(I)$ of $\mathrm{CO}_{2}$ band of bare THH Pt NCs and Au-decorated THH Pt NCs in Fig. 5A and B. (D) The intensity (peak to peak value) of $\mathrm{CO}_{\mathrm{L}}$ band of THH Pt NCs and Au-decorated THH Pt Ns in Fig. $5 \mathrm{~A}$ and $\mathrm{B}$.

potential of $\mathrm{CO}_{\mathrm{ads}}$, the enhanced yield of $\mathrm{CO}_{2}$ at the decorated THH Pt NCs must arise from an Au adatom induced switch in the $\mathrm{HCOOH}$ oxidation mechanism towards the dehydrogenation pathway. This point is further emphasised by comparing the spectra of Fig. 5A and B, with those presented elsewhere ${ }^{59}$ for methanol electrooxidation at Ru decorated THH Pt NCs. In the $\mathrm{Ru}$ decorated case the onset of the $\mathrm{CO}_{2}$ signal was $100 \mathrm{mV}$ lower at decorated compared with the clean Pt surfaces, indicating that the $\mathrm{Ru}$ adatoms had the effect of reducing the onset potential for $\mathrm{CO}_{\text {ads }}$ oxidation. By contrast the onset potential of the $\mathrm{CO}_{2}$ formation is the same for $\mathrm{THH}$ Pt NCs with $\theta_{\mathrm{Au}}=0$ or 0.74 in Fig. 5A and B. The improved catalytic activity displayed by the latter is therefore due, not to a bifunctional effect, but rather to an increase in the importance of the direct relative to the indirect $\mathrm{HCOOH}$ oxidation pathway.

The FTIR data in Fig. 5 provide time averaged information on $\mathrm{CO}_{2}$ formation at various potentials. Further evidence of 


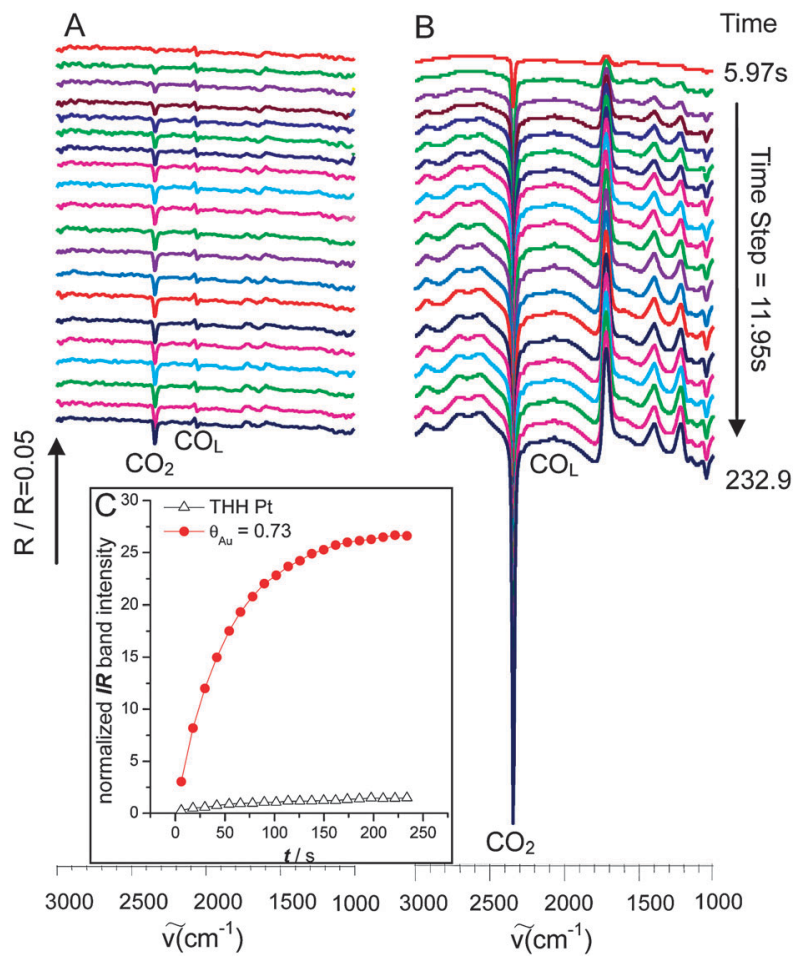

Fig. 6 In situ time-resolved FTIR spectra obtained for THH Pt NCs (A), Au-decorated THH Pt NCs $\left(\theta_{\mathrm{Au}}=0.73\right)(\mathrm{B})$, in $0.25 \mathrm{M} \mathrm{HCOOH}+$ $0.1 \mathrm{M} \mathrm{H}_{2} \mathrm{SO}_{4}$ solution with $E_{\mathrm{S}}$ at $0.1 \mathrm{~V}$ and $E_{\mathrm{R}}$ at $-0.25 \mathrm{~V}$. For each single beam, 32 interferograms were added and the resolution was $16 \mathrm{~cm}^{-1}$. (C) Variation of intensity $(I)$ of $\mathrm{CO}_{2}$ band of THH Pt NCs and Au-decorated THH Pt NCs in Fig. 6A and B was normalized by the active surface area of each electrode.

the superiority, with respect to $\mathrm{CO}_{2}$ production, of the $\theta_{\mathrm{Au}}=$ $0.73 \mathrm{THH}$ electrode over the clean surface can be obtained by examining the time-dependent FTIR spectra collected at a given potential. Time resolved FTIR measurements recorded over $11.95 \mathrm{~s}$ intervals at $E=0.1 \mathrm{~V}$ in $0.25 \mathrm{M} \mathrm{HCOOH}+$ $0.1 \mathrm{M} \mathrm{H}_{2} \mathrm{SO}_{4}$ solution are presented in Fig. 6A and $\mathrm{B}$ for both clean and $\mathrm{Au}$ decorated surfaces $\left(\theta_{\mathrm{Au}}=0.73\right)$. Fig. $6 \mathrm{C}$ shows the integrated intensity of the $2341 \mathrm{~cm}^{-1} \mathrm{CO}_{2}$ band against the sampling potential for the two electrodes. These data demonstrate that the rate of $\mathrm{CO}_{2}$ formation is significantly higher from the decorated surface in comparison to the clean electrode. In fact the quantity of $\mathrm{CO}_{2}$ accumulated after $232 \mathrm{~s}$ in the electrolyte thin layer between the electrode and the IR window is enhanced by approximately an order of magnitude by the presence of the Au adatoms on the THH Pt.

\section{Conclusions}

The decoration of THH Pt NC surfaces by $\mathrm{Au}$ adatoms has been achieved through the galvanic replacement of the submonolayer of underpotential deposited $\mathrm{Cu}$ adatoms. The Au-decorated Pt surfaces were characterised by cyclic voltammetry, with the decrease in the hydrogen adsorption/desorption charge used as a measure of the adatom coverage, $\theta_{\mathrm{Au}}$. The voltammetric profile for formic acid electrooxidation at the clean THH Pt surface is typical of that previously observed for other Pt electrodes. It consists of a low current plateau at $c a .0 .25-0.45 \mathrm{~V}$ and a much higher current peak just above $0.6 \mathrm{~V}$. The relative charge associated with the former feature increases progressively at the expense of the latter, as the $\mathrm{Au}$ coverage is raised to $\theta_{\mathrm{Au}}=0.72$, indicating a switch in the reaction mechanism from the indirect (dehydration) pathway to the direct (dehydrogenation) route. This ability of the $\mathrm{Au}$ adatoms to effect an increase in activity at lower potentials is also reflected in chronoamperometry data with a current enhancement factor of over 15 observed at $E=0.05 \mathrm{~V}$ for the electrode with $\theta_{\mathrm{Au}}=0.72$ compared with clean THH Pt NCs.

In situ FTIR measurements reveal much higher yields of $\mathrm{CO}_{2}$ from an $\mathrm{Au}$ decorated THH Pt NC surface $\left(\theta_{\mathrm{Au}}=0.74\right)$ compared to the unmodified surface across the potential region ( $<c a$. $0.25 \mathrm{~V}$ vs. SCE) of technical relevance to direct formic acid fuel cell development. Significantly, the onset potential for $\mathrm{CO}_{2}$ formation is not reduced by $\mathrm{Au}$ modification. This observation in tandem with the results of anodic $\mathrm{CO}_{\mathrm{ads}}$ stripping experiments suggests that the beneficial impact of the $\mathrm{Au}$ adatoms may be attributed to a third body effect. Combining well-defined, high-index facetted Pt surfaces with an oxidation resistant additive of $\mathrm{Au}$ adatoms, we have described a nano-engineered material which marks progress in the transfer of model electrocatalysis to the practical realm.

\section{Acknowledgements}

This study was supported by Major State Basic Research Development Program of China (2012CB215500), NSFC (20933004, 21073152, 20833005, and 21021002), Foundation for the Author of National Excellent Doctoral Dissertation of China (201126), Fundamental Research Funds for the Central Universities (2010121021), and Program for New Century Excellent Talents in University (NECT-11-0301 and NECT10-0715). M.P.B., C.H., and W.-F.L. gratefully acknowledge financial support from Queen's University Belfast (The ISW DEL Clean Energies) and the EPSRC (EP/I013229/1).

\section{Notes and references}

1 Z.-Y. Zhou, N. Tian, Z.-Z. Huang, D.-J. Chen and S.-G. Sun, Faraday Discuss., 2008, 140, 81-92.

2 Z. Peng and H. Yang, Nano Today, 2009, 4, 143-164.

3 Y. Xia, Y. Xiong, B. Lim and S. E. Skrabalak, Angew. Chem., Int. Ed., 2009, 48, 60-103.

4 S. Cheong, J. D. Watt and R. D. Tilley, Nanoscale, 2010, 2, 2045-2053.

5 T. K. Sau and A. L. Rogach, Adv. Mater., 2010, 22, 1781-1804.

6 J. Solla-Gullon, F. J. Vidal-Iglesias and J. M. Feliu, Annu. Rep. Prog. Chem., Sect. C, 2011, 107, 263-297.

7 Z.-Y. Zhou, N. Tian, J.-T. Li, I. Broadwell and S.-G. Sun, Chem. Soc. Rev., 2011, 40, 4167-4185.

8 N. Tian, Z.-Y. Zhou and S.-G. Sun, J. Phys. Chem. C, 2008, 112, 19801-19817.

9 J. Solla-Gullon, P. Rodriguez, E. Herrero, A. Aldaz and J. M. Feliu, Phys. Chem. Chem. Phys., 2008, 10, 1359-1373.

10 J. Solla-Gullon, F. J. Vidal-Iglesias, A. Lopez-Cudero, E. Garnier, J. M. Feliu and A. Aldaz, Phys. Chem. Chem. Phys., 2008, 10, 3689-3698.

11 I.-S. Park, K.-S. Lee, J.-H. Choi, H.-Y. Park and Y.-E. Sung, J Phys. Chem. C, 2007, 111, 19126-19133.

12 E. Leiva, T. Iwasita, E. Herrero and J. M. Feliu, Langmuir, 1997, 13, 6287-6293.

13 X. Yu and P. G. Pickup, J. Power Sources, 2008, 182, 124-132. 
14 R. Wang, C. Wang, W.-B. Cai and Y. Ding, Adv. Mater., 2010, 22, $1845-1848$.

15 C. Lamy, A. Lima, V. LeRhun, F. Delime, C. Coutanceau and J.-M. Leger, J. Power Sources, 2002, 105, 283-296.

16 A. Capon and R. Parsons, J. Electroanal. Chem., 1973, 45, 205-231.

17 T. Iwasita, X. Xia, E. Herrero and H.-D. Liess, Langmuir, 1996, 12, 4260-4265.

18 A. Miki, S. Ye and M. Osawa, Chem. Commun., 2002, 1500-1501.

19 S. Park, Y. Xie and M. J. Weaver, Langmuir, 2002, 18, 5792-5798.

20 V. Grozovski, J. Solla-Gullon, V. c. Climent, E. Herrero and J. M. Feliu, J. Phys. Chem. C, 2010, 114, 13802-13812.

21 V. Grozovski, V. Climent, E. Herrero and J. M. Feliu, Phys. Chem. Chem. Phys., 2010, 12, 8822-8831.

22 V. Grozovski, V. Climent, E. Herrero and J. M. Feliu, ChemPhysChem, 2009, 10, 1922-1926.

23 S.-G. Sun and Y.-Y. Yang, J. Electroanal. Chem., 1999, 467, $121-131$

24 S. G. Sun and J. Clavilier, Chem. J. Chin. Univ., 1990, 11, 998-1002.

25 S. C. Chang, L. W. H. Leung and M. J. Weaver, J. Phys. Chem. B, 1990, 94, 6013-6021.

26 J. Clavilier, J. M. Feliu, A. Fernandez-Vega and A. Aldaz, J. Electroanal. Chem., 1989, 269, 175-189.

27 J. Clavilier, J. Electroanal. Chem., 1987, 236, 87-94.

28 N. Tian, Z.-Y. Zhou, S.-G. Sun, Y. Ding and Z. L. Wang, Science, 2007, 316, 732-735.

29 S.-G. Sun, A.-C. Chen, T.-S. Huang, J.-B. Li and Z.-W. Tian, J. Electroanal. Chem., 1992, 340, 213-226.

30 Q.-S. Chen, Z.-Y. Zhou, F. J. Vidal-Iglesias, J. Solla-Gullon, J. M. Feliu and S.-G. Sun, J. Am. Chem. Soc., 2011, 133, 12930-12933.

31 J. S. Spendelow and A. Wieckowski, Phys. Chem. Chem. Phys., 2004, 6, 5094-5118.

32 F. J. Vidal-Iglesias, J. Solla-Gullón, E. Herrero, A. Aldaz and J. M. Feliu, Angew. Chem., Int. Ed., 2010, 49, 6998-7001.

33 X. Wang, J.-M. Hu and I. M. Hsing, J. Electroanal. Chem., 2004, 562, 73-80.

34 F. S. Thomas and R. I. Masel, Surf. Sci., 2004, 573, 169-175.

35 C. Rice, S. Ha, R. I. Masel and A. Wieckowski, J. Power Sources, 2003, 115, 229-235.

36 M. Arenz, V. Stamenkovic, T. J. Schmidt, K. Wandelt, P. N. Ross and N. M. Markovic, Phys. Chem. Chem. Phys., 2003, 5, 4242-4251.

37 P. Waszczuk, T. M. Barnard, C. Rice, R. I. Masel and A. Wieckowski, Electrochem. Commun., 2002, 4, 599-603.

38 S. Daniele and S. Bergamin, Electrochem. Commun., 2007, 9, $1388-1393$.

39 E. Casado-Rivera, D. J. Volpe, L. Alden, C. Lind, C. Downie, T. Vazquez-Alvarez, A. C. D. Angelo, F. J. DiSalvo and H. c. D. Abruna, J. Am. Chem. Soc., 2004, 126, 4043-4049.

40 M. D. Maciá, E. Herrero, J. M. Feliu and A. Aldaz, J. Electroanal. Chem., 2001, 500, 498-509.
41 L. R. Alden, C. Roychowdhury, F. Matsumoto, D. K. Han, V. B. Zeldovich, H. c. D. Abruna and F. J. DiSalvo, Langmuir, 2006, 22, 10465-10471.

42 J.-H. Choi, K.-J. Jeong, Y. Dong, J. Han, T.-H. Lim, J.-S. Lee and Y.-E. Sung, J. Power Sources, 2006, 163, 71-75.

43 M. D. Obradović, A. V. Tripković and S. a. L. Gojković, Electrochim. Acta, 2009, 55, 204-209.

44 S. Zhang, Y. Shao, H.-g. Liao, J. Liu, I. A. Aksay, G. Yin and Y. Lin, Chem. Mater., 2011, 23, 1079-1081.

45 C. Venkateswara Rao, C. R. Cabrera and Y. Ishikawa, J. Phys. Chem. C, 2011, 115, 21963-21970.

$46 \mathrm{~J}$. Liu, L. Cao, W. Huang and Z. Li, ACS Appl. Mater. Interfaces, $2011,3,3552-3558$.

47 J. B. Xu, T. S. Zhao and Z. X. Liang, J. Power Sources, 2008, 185, $857-861$.

48 J. K. Lee, J. Lee, J. Han, T.-H. Lim, Y.-E. Sung and Y. Tak, Electrochim. Acta, 2008, 53, 3474-3478.

49 G. Chen, Y. Li, D. Wang, L. Zheng, G. You, C.-J. Zhong, L. Yang, F. Cai, J. Cai and B. H. Chen, J. Power Sources, 2011, 196, 8323-8330.

50 C. Qiu, Y. Guo, J. Zhang, H. Ma and Y. Cai, Mater. Chem. Phys., 2011, 127, 484-488.

51 D. Zhao, Y.-H. Wang and B.-Q. Xu, J. Phys. Chem. C, 2009, 113, 20903-20911.

52 N. Kristian, Y. Yu, P. Gunawan, R. Xu, W. Deng, X. Liu and X. Wang, Electrochim. Acta, 2009, 54, 4916-4924.

53 S. N. Pron'kin, G. A. Tsirlina, O. A. Petrii and S. Y. Vassiliev, Electrochim. Acta, 2001, 46, 2343-2351.

54 C. Jin, C. Sun, R. Dong and Z. Chen, Electrochim. Acta, 2010, 56, $321-325$.

55 J. Zhang, K. Sasaki, E. Sutter and R. R. Adzic, Science, 2007, 315, 220-222.

56 J.-T. Li, Q.-S. Chen and S.-G. Sun, Electrochim. Acta, 1997, 52, $5725-5732$.

57 R. Woods, in Electroanalytical Chemistry. A Series of Advances, ed. A. J. Bard, Marcel Dekker, New York, 1976, pp. 1-162.

58 S. Trasatti and A. Petri, Pure Appl. Chem., 1991, 63, 711-734.

59 H.-X. Liu, N. Tian, M. P. Brandon, Z.-Y. Zhou, J.-L. Lin, C. Hardacre, W.-F. Lin and S.-G. Sun, ACS Catal., 2012, 2, $708-715$.

60 J. D. Lovic, A. V. Tripkovic, S. L. Gojkovic, K. D. Popovic, D. V. Tripkovic, P. Olszewski and A. Kowel, J. Electroanal. Chem., 2005, 581, 294-302.

61 G. Samjeske, A. Miki, S. Ye and M. Osawa, J. Phys. Chem. B, 2006, 110, 16559-16566.

62 M. Neurock, M. Janik and A. Wieckowski, Faraday Discuss., 2009, 140, 363-378.

63 A. Cuesta, ChemPhysChem, 2011, 12, 2375-2385.

64 A. Miki, S. Yeb and M. Osawa, Chem. Commun., 2002, 1500-1501.

65 Y.-Y. Yang, Z.-Y. Zhou and S.-G. Sun, J. Electroanal. Chem., 2001, 500, 233-240.

66 G. Samjeske, A. Miki, S. Ye and M. Osawa, J. Phys. Chem. B, 2006, 110, 16559-16566. 